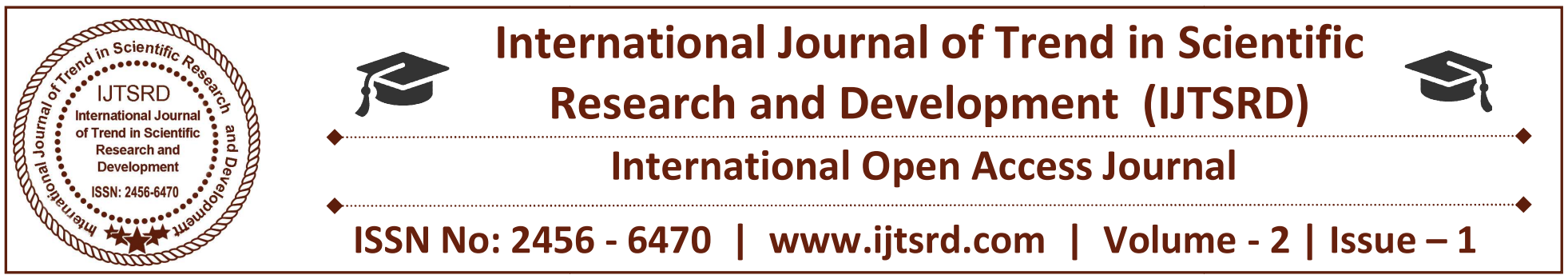

\title{
Role of Instrumentation Data Analysis in Safety Monitoring of Giant Structures
}

\author{
B Datta \\ Associate Professor, College of Military \\ Engineering, Pune, Maharastra
}

\begin{abstract}
The importance of Safety monitoring of old structures e.g., Bridges, Dams etc need not be overemphasized. Monitoring of several significant parameters always essential for prediction of structural behavior of the unit. Need for proper calibration and maintenance of embedded instruments are discussed. Recording of data collected in a regular interval on site from few significant instruments embedded in the structure followed by Statistical analysis of correlated data is an important tool for health monitoring of structure. The issue is discussed with a mention of dam instrumentation and data analysis. It helps in commenting about trend of permanent settlement component of dam deflection of a few geographically supported dam, hence justifies instrumentation in giant structures from safety point of view in turn.
\end{abstract}

\section{INTRODUCTION}

Giant structures like dams are perfect example of sustainable Engineering which provides a range of economic, environmental, and social benefits, including renewable hydroelectric power generation, irrigation, water supply, flood control, and tourism. Though the risk of a well designed and constructed dam collapsing is extremely low, still there exists a high danger potential in terms of human and economic loss on accident. This high potential makes it essential to monitor structural behavior of a Unit and ensure its safety. Similar action of continuous health monitoring by instrumentation data recording and analysis would be useful for timely action taking for rehabilitation of other important giant structures in their old age. Finite Element Method(1), Neural Networking(2), Remote Sensing /
GPS data analysis (3) or Statistical Predictive Model using dam instrumentation data analysis(4,5) are various leading techniques may be mentioned as effective tools in this regard. Dam instrumentation data analysis by the hydrostatic load-temperature gradient-seasonal periodic effect-time elapsed method is fully implemented in engineering practice for geographically suitable gravity dam or monolithic cantilever type concrete structure. It enables to provide continued assurance of the safety of structure, and helps in undertaking timely remedial measures in case of discrepancies between the expected and observed values of safety parameters are noticed. It also provides a deeper insight into the design assumptions and criteria, in turn, leading to improvement in future from expenditure and safety point of view. Various causes of failure in structures like Dams are highlighted by PR Bamane et al(6).

Big structures are many a times not properly instrumented. For example, there are around 4300 completed/ under construction large dams / hydraulic structures in our country besides a very large number of medium and minor dams. However, the scenario on the instrumentation of such structures is not encouraging as it is found that only 5 percent are instrumented/proposed to be instrumented. A distribution of instrumented hydraulic structures in few states which have more than 100 large completed /under construction hydraulic structures (7) is given in Fig 1. Although the data is old, however improvement in status till date is not remarkable. It suggests more number of hydraulic structures needs to be instrumented and their structural behavior be monitored for prediction of possible failures. 


\section{DAM INTRUMENTATION AND DATA RECORDING}

Under normal geographical condition, most of the dams are gravity dam constructed in several concrete monoliths which behave like cantilever fixed at one end. Variable hydrostatic load in upstream and thermal effect due to temperature gradient (causes due the instrumentation data comprehensively and develop suitable mathematical models based on data collected for making forecast of important parameters such as deflection, seepage etc. There is also a greater need to adopt automated data acquisition and processing system which can enhance the ability of engineering personnel to evaluate

\section{Distribution of Hydraulic structures/ instrumented hydraulic structures}

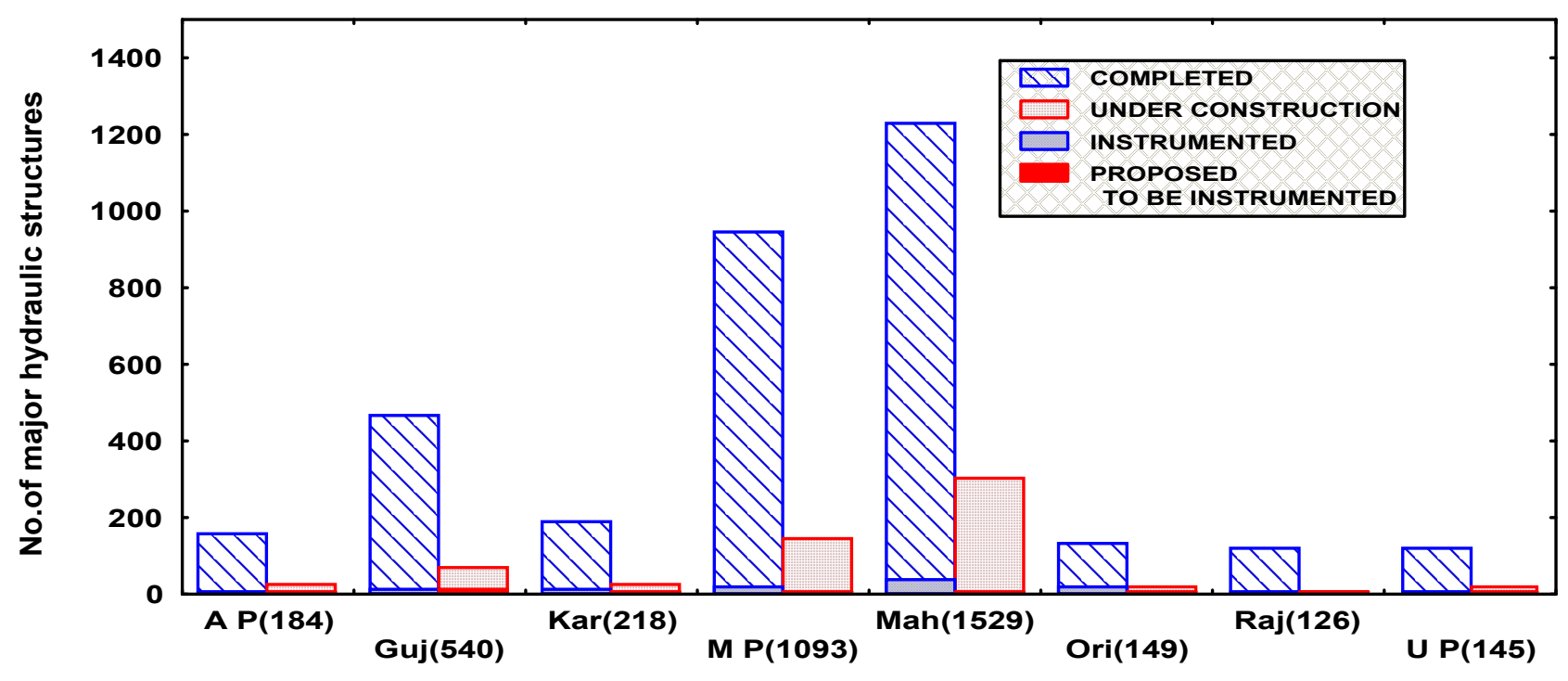

Fig.1

to sun exposure-no exposure as well as prolonged exothermic reactions within thick concrete structure) between upstream and downstream are the main causes for cantilever deflection. Hence, apart from horizontal shift or earth quake effects which are accidental in nature, vertical deflection of central monolith cantilever is a vital parameter to be investigated as it speaks maximum. Ideally, every dam needs to be properly instrumented mainly in central monoliths during construction stage only, Various instruments such as coordimeters, microscope, stress meter, strain gauges, uplift pipe, pore pressure cells, piezometers, thermometers, water level recorder, tiltmeter, seismograph, joint meter etc. are installed in modern dams and data is collected periodically and analysed. Installation of proper Instrumentation in Dam is well discussed by Chavan et al (8) and Bartholomew et al (9). On the examination of the status of analysis of instrumentation data collected, it is found that many a places the data is only amassed and the preliminary analysis is carried out at local research Institutes and the findings kept confined to the project authorities. There is need to create awareness amongst the project officials and engineers in charge of maintenance section that sophisticated techniques are available to process performance and safety monitoring of structures to overcome potential threat to public safety.

The procedure followed during the recording of various observations is equally important from the view point of its quick processing. To facilitate quick and meaningful processing of data, the following steps may be followed:

a) Post Installation, embedded Instruments must be under annual maintenance and calibration.

b) Data recording is essential in equal interval of time and needs to be verified by experts.

c) Data be reviewed once in every month for any ambiguity.

d) Yearly data needs to be compared with previous year data.

\section{DATA PROCESSING TO ESTIMATE DEFLECTION OF DAM}

It is well accepted that safety of dam does not mean merely collecting instrument data during operation of dam, but mainly a question of analysis cum interpreting such data and draw conclusions for taking suitable decisions at appropriate time. A detailed account of models used in interpretation of data can be obtained from publication of P.Bonaldi et al $(10,11)$. Posteriori models (statistical) are the most 
widely used, both because of their simplicity and the good results they usually give. The method has been used by Ryoji Mike and I.Kobayashi (12) in the safety control of arch dams while simple regression technique has been reported to be used by N.L.de.S.Pinto et al(13) for estimating the maximum face deflection in concrete face rock fill dams. B Pant et al (14) have used the model for forecasting the deflection of gravity dam employing theory of linear multiple regression.

These models are based on the consideration that deflection in a dam are, as an initial approximation, the net result of mainly two different effects viz. hydrostatic effect and thermal effect. Correlation study of recorded deflection data with hydrostatic load and thermal data reported for various dams suggest that nearly $90 \%$ deflection caused by hydrostatic load, whereas thermal effect contributes $10 \%$ on net deflection in opposite direction. Remaining $20 \%$ deflection are due to various other factors e.g., cyclic seasonal effect as well as irreversible effect/permanent settlement. Permanent settlement component of cantilever deflection must be within permissible limit. Hence, it is suggested that installation of a few instruments like deflection meter, temperature sensors and water level meter, followed by collection of data from these instruments in a regular manner and statistical data analysis by regression method etc may give an insight about safety of dam as far as permanent component of deflection is concerned.

Health monitoring of giant structures can also be performed by developing suitable mathematical model or finite element study for static/dynamic loading. In every cases, data recorded by embedded instruments play a key role for drawing logical conclusions.

\section{CONCLUSION}

(i) Data carries information. Hence instrumentation data needs to be collected in systematic manner for any big structure to monitor its health or for rehabilitation of old structures.

(ii) Accuracy of the mathematical model as applicable/developed for a particular giant structure depends on incorporation of variables in the model as maximum as possible. For example, variation of hydrostatic load in upstream is not cyclic in a year, rather it is a saw tooth in nature but for simplicity/approximation, sinusoidal variation is considered. Hence, developing dedicated statistical model, knowledge of basic science plays a vital role.

(iii) A lot of scope exists in Dam safety management system (15) and obviously for safety management of any old structures.

(iv) Discussion may be well extended for rehabilitation of old and giant structures for health monitoring.

(v) Statistical predictive study supports decision to alteration in structure like further increase in dam height to raise the reservoir capacity, if expansion of catchment area is permissible etc.

\section{ACKNOWLEDGEMENTS}

The author is grateful to the Commandant, College of Military Engineering, Pune for giving permission to publish this paper.

\section{REFERENCES}

1) Anna Szostak-chrzanowski et al, Study of a long term behavior of large earth dam combining monitoring and finite element analysis results, Proceedings of $13^{\text {th }}$ International Symposium on Deformation measurements and analysis, Lisbon, May 12-15, 2008.

2) J Mata, Interpretation of Concrete dam behavior with artificial neural network and multiple linear regression models, Engineering Structures, Vol 33, Issue 3, pp 903-10, March 2011.

3) Ankur Manake et al, Study of the Deformation of Koyna dam using the Global Positioning System, Survey Review, Vol 36, Issue 385, 2002.

4) LF Chouinard et al, Statistical Analysis of Monitoring Data for concrete Arch Dams, Journal of Performance of construction facilities, ASCE, Vol 9, Issue 4, Nov 1995.

5) Hong $\mathrm{Yu}$ et al, Multivariate Analysis in dam monitoring data with PCA, Science China Technological Sciences, Vol 53, issue 4, pp 10881097, Apr 2010.

6) PR Bamane et al, Dam Safety Instrumentation, American Journal of Engineering Research, eISSN 2320-0847, Vol 3, Issue 6, pp 58-62, 2014.

7) Central Water Commission, New Delhi Publication No.19/96 'Status of Instrumented hydraulic structures in India', 1996.

8) AR Chavan et al, A study of Instruments used for Dam Instrumentation in Gravity and Earthen 
Dams, IJETR, ISSN 2321-0869, Vol 3, Issue 5, May 2015.

9) CL Bartholomew et al, Concrete Dam Instrumentation Manual, University of Massachusetts Amharst, Scholarworks.umass.edu. 1987.

10) P. Bonaldi et al, 'Automatic observation and Instantaneous control of dam safety' Part two : A priori deterministic models and a posteriori models workshop on Influence of creep on design, performance and safety of concrete dams, Vol. I, pp 201-269, July1993,New Delhi.

11) P. Bonaldi et al, Displacement forecasting for concrete dams, Water Power and Dams construction, pp 42-50, September 1977.

12) Ryoji Milke d et al, Safety control of arch dams by regression model, Design of Hydraulic

13) Structures, Ed: M.L.Albertson, R.A.Kia, Balkema, Amsterdam, 1989. N.L.de S.Pinto et al, Estimating the maximum face deflections in CFRDS, Hydropower and Dams, Issue 6, 1998.

14) B.Pant et al, A mathematical model for forecasting displacement of the Koyna dam, Irrigation and Power, pp 247-253, July 1979.

15) Jesung Jeon et al, Development of dam safety management System, Advances in Engineering Software, Elsevier, Vol 40, Issue 8, August 2009. 